\title{
Da teoria matemática para uma proposta de teoria crítica da informação:a integração dos conceitos de regime de informação e competência crítica em informação
}

\author{
Arthur Coelho Bezerra ${ }^{I}$ \\ http://orcid.org/0000-0001-5445-6263
}

I Instituto Brasileiro de Informação em Ciência e Tecnologia (IBICT), RJ, Brasil. Professor do Programa de Pós-graduação em Ciência da Informação (PPGCI/IBICT-UFRJ).

http://dx.doi.org/10.1590/1981-4026

Iniciamos nosso estudo com uma contextualização histórico-crítica da teoria matemática da comunicação de Shannon e Weaver, reconhecendo a importância de sua influência na consolidação da ciência da informação nos Estados Unidos e apontando os limites de sua intenção unidimensional. A análise serve de mote para a apresentação da teoria crítica da sociedade, desenvolvida no mesmo período por filósofos alemães da chamada Escola de Frankfurt. Seus fundamentos teóricometodológicos irão nortear nossa proposta para uma teoria crítica da informação, pensada a partir da integração de dois conceitos caros à ciência da informação brasileira: o de regime de informação, entendido como recurso interpretativo para pensar as relações entre política, informação e poder, e o de competência crítica em informação, que traz contribuições da teoria frankfurtiana e da pedagogia freireana para sublinhar a 
avaliação crítica e o uso ético da informação. Nosso método sugere a proposição de um diagnóstico das potencialidades, limites e contradições dos regimes de informação dominantes, e encontra na gramática da competência crítica em informação o referencial de uma práxis voltada à ampliação da autonomia dos indivíduos no atual ecossistema informacional, fundamental para o exercício da cidadania em tempos de desinformação, mediação algorítmica, vigilância digital e ataques à privacidade.

Palavras-chave: Teoria crítica da informação; Teoria matemática da comunicação; Regime de informação; Competência crítica em informação; Competência em informação.

We begin our study with a historical-critical contextualization of Shannon and Weaver's mathematical communication theory, recognizing the importance of its influence in the consolidation of the information science field in the United States and pointing out the limits of its one-dimensional intention. The analysis serves as a motto for the presentation of the critical theory of society, developed in the same period by German philosophers of the so-called Frankfurt School. Its theoreticalmethodological foundations will guide our proposal for a critical information theory, conceived from the integration of two popular concepts in the Brazilian information science: régime of information, understood as an interpretative resource to think the relations between politics, information and power, and critical information literacy, which brings the contributions of the Frankfurtian theory and the Freirean pedagogy to underline the critical evaluation and the ethical use of information. Our method suggests the proposition of a diagnosis of the potentialities, limits and contradictions of the dominant régime of information, and finds in the grammar of the critical information literacy the reference of a praxis aimed at the extension of the autonomy in the present informational ecosystem, fundamental for the exercise of 
citizenship in times of disinformation, algorithmic mediation, digital surveillance and privacy attacks.

Keywords: Critical information theory; Mathematical communication theory; Régime of information; Critical information literacy; Information literacy.

Recebido em 21.06.2019 Aceito em 30.07.2020

\section{Introdução}

É compreensível, considerando a característica interdisciplinar tantas vezes atribuída à ciência da informação, que a bibliotecária Maura Seale se surpreenda com o fato de que a disciplina demonstre um engajamento tão modesto com as perspectivas teóricas do pensamento crítico, especialmente tendo em vista a preocupação da área com as formas de produção do conhecimento e com a estruturação de sistemas e práticas informacionais (SEALE, 2013, p. 40). O espanto da pesquisadora estrangeira pode ser, em alguma medida, confirmado pelo estudo de Carlos Alberto Araújo a respeito das manifestações e ausências do pensamento crítico na ciência da informação: em que pese o reconhecimento do desenvolvimento não linear desta ou de qualquer área científica, entendida pelo autor como um campo de forças em disputa, é admitida a existência de um "núcleo duro" da ciência da informação, "que seria formado pelas questões técnicas e que seria o centro do campo, sendo as questões políticas, sociais e culturais da informação temas da 'periferia', menos importantes" (ARAúJO, 2013, p. 25). A expressão "núcleo duro" é creditada por Araújo a Lena Vânia Pinheiro, uma das pesquisadoras brasileiras que mais destacam a vocação interdisciplinar da ciência da informação, concebendo-a no sentido de uma "intensidade das trocas entre especialistas e pelo grau de interação real das disciplinas, no interior de um projeto específico de pesquisa" (PINHEIRO, 1997, p. 49).

Se as interações com disciplinas como biblioteconomia, comunicação social, ciência da computação, arquivologia e museologia permitem que a ciência da informação amplie seus repertórios de saberes, a aproximação com os campos da filosofia crítica, da sociologia crítica e da pedagogia crítica também promete fecundos alargamentos epistêmicos. Semelhante aproximação, em nosso entendimento, pode estimular um exercício de autoanálise da área a partir da historiografia crítica e reflexiva de sua consolidação como campo científico - o que, nos Estados Unidos, ocorre 
em meados do século $X X$, contando com a notável contribuição dos matemáticos Claude Shannon, Warren Weaver e Norbert Wiener.

A contextualização histórico-crítica da teoria matemática da comunicação de Shannon e Weaver no alvorecer da ciência da informação norteamericana é o ponto de partida do presente estudo, servindo de mote para a subsequente apresentação da teoria crítica da sociedade, desenvolvida no mesmo período (e no mesmo país) por filósofos alemães como Max Horkheimer, Theodor W. Adorno e Herbert Marcuse, integrantes do Instituto para a Pesquisa Social, conhecido mundialmente como Escola de Frankfurt. Os fundamentos teórico-metodológicos da teoria crítica frankfurtiana irão orientar nossa proposta para uma teoria crítica da informação, pensada a partir da integração de dois conceitos caros à ciência da informação brasileira: o conceito de regime de informação, entendido como recurso interpretativo para pensar as relações entre política, informação e poder, e o de competência crítica em informação, que traz contribuições da teoria frankfurtiana e da pedagogia de Paulo Freire para sublinhar a avaliação crítica e o uso ético da informação.

Nosso método sugere a proposição de um diagnóstico das potencialidades, limites e contradições do regime de informação dominante que vigora nas redes digitais, e encontra na gramática da competência crítica em informação o referencial de uma práxis voltada para a ampliação da liberdade e da autonomia dos indivíduos no atual ecossistema informacional, condições consideradas fundamentais para o exercício da cidadania em tempos de desinformação, mediação algorítmica, vigilância digital e toda a sorte de ataques à privacidade.

\section{Uma teoria unidimensional}

Durante o quarto de século que compreende o hiato entre o fim da Segunda Guerra Mundial (1945) e as crises econômicas e políticas da década de 1970, muitos países vivenciaram uma época gloriosa. Em seu livro sobre o "breve século XX", o historiador Eric Hobsbawm (1995) conta que, no período do pós-guerra conhecido como "Era de Ouro", investimentos em pesquisa e desenvolvimento tornam-se fundamentais para o crescimento econômico almejado por nações ao redor do mundo, reforçando a vantagem das economias de mercado desenvolvidas sobre as demais. Ao mesmo tempo, o processo de inovação impulsionado pelas grandes guerras passa a ser visto como algo contínuo, aumentando a fração dos custos de produção que empresas e indústrias dedicam ao desenvolvimento de novos produtos.

Os anos de guerra, nas palavras de Hobsbawm, foram "singularmente bondosos" com os Estados Unidos, país que chegou ao fim do conflito sem grandes danos, com crescimento do PIB em dois terços e responsável por dois terços da produção industrial do mundo 
(HOBSBAWM, 1995, p. 254). O sucesso da tecnologia norte-americana na Segunda Guerra, bem como o estímulo para a pesquisa científica e tecnológica do país nos anos dourados que a sucedem, contou com a contribuição de um grande número de cientistas norte-americanos, dentre os quais dois matemáticos que se tornariam referência para a ciência da informação: Claude Shannon e Warren Weaver.

Weaver, o mais velho, nasceu em 1894, mesmo ano do criador da cibernética, Norbert Wiener, também um matemático estadunidense de grande relevância para o desenvolvimento científico e tecnológico mundial. Ambos, Weaver e Wiener, desenvolveram trabalhos em computação, automação e controle, temas caros à ciência e ao comando militar norte-americano da época. Suas trajetórias, no entanto, são distintas: se Wiener possui um perfil mais engajado com a crítica filosófica, levantando preocupações a respeito da militarização da ciência, das implicações éticas do trabalho de seus colegas e da interferência política na pesquisa científica, Weaver se aproxima da figura do gestor institucional dotado de traquejo político, tendo sido chefe da Natural Sciences Division, da Rockefeller Foundation, e membro do National Defense Research Committee (NDRC), criado por Vannevar Bush em 1940 para sensibilizar a universidade e a pesquisa industrial para a resolução de problemas militares. Em seus anos de atividade durante a guerra, o NDRC financiou dezenas de projetos científicos e tecnológicos, de veículos anfíbios a bombas nucleares (o chamado Projeto Manhattan).

Na Rockefeller Foundation, a gestão de Weaver foi responsável pela aprovação de projetos em pesquisa médica, genética, engenharia molecular e agricultura. No entanto, não foram as habilidades administrativas que o tornaram conhecido na comunidade acadêmica internacional, e sim a coautoria do livro The Mathematical Theory of Communication, escrito em 1949 em parceria com Claude Shannon, um prodígio matemático e engenheiro elétrico, 22 anos mais jovem que Weaver.

Assim como Weaver, Shannon colaborou com a defesa nacional dos EUA durante a Segunda Guerra, escrevendo o memorando A Mathematical Theory of Cryptography para o NDRC, em 1945. Após algumas restrições de confidencialidade, o documento foi disponibilizado ao público com o título Communication Theory of Secrecy Systems, mantendo as mesmas formulações e conceitos matemáticos de computação e criptografia que Shannon utiliza no famoso artigo Mathematical Theoryof Communication, de 1948. O livro de Shannon e Weaver, publicado no ano seguinte, contém uma reprodução deste artigo de Shannon, precedido por um capítulo inédito de Weaver que consiste em uma exposição introdutória dos conceitos propostos por seu jovem colega. 
Desde a introdução do artigo, Shannon deixa claro o recorte epistemológico que propõe para a sua teoria da comunicação:

O problema fundamental da comunicação é reproduzir em um ponto exatamente ou aproximadamente uma mensagem selecionada em outro ponto. Frequentemente as mensagens têm significado; isto é, elas se referem ou são correlacionadas a algum sistema com certas entidades físicas ou conceituais. Esses aspectos semânticos da comunicação são irrelevantes para o problema de engenharia (SHANNON; WEAVER, 1964, p. 31, tradução nossa)

O alcance teórico proposto por Shannon é comentado no capítulo introdutório de Weaver, que divide os problemas da comunicação em três níveis: o primeiro refere-se à precisão com a qual os símbolos de comunicação podem ser transmitidos, caracterizando-se como um problema técnico; o segundo diz respeito à precisão com a qual os símbolos transmitidos carregam o significado desejado, configurando-se em um problema semântico; e o último está relacionado ao grau de eficácia com que o significado recebido afeta a conduta da maneira desejada, sendo, portanto, um problema de eficácia (SHANNON; WEAVER, 1964, p. 4). A opção de Shannon em concentrar seus esforços apenas no primeiro nível de análise, ou seja, no que chamou de "problema de engenharia", permitiu-o utilizar conceitos matemáticos como os de entropia e probabilidade para mensurar, a partir de um esquema linear que conecta uma fonte a um receptor, a máxima quantidade de informação possível de ser selecionada e enviada através de determinado canal. Nos limites da teoria de Shannon, conforme esclarece Weaver, "duas mensagens, uma das quais é fortemente carregada de significado e a outra é puro nonsense, podem ser exatamente equivalentes, do ponto de vista presente, em relação à informação" (SHANNON; WEAVER, 1964, p. 8, tradução nossa).

Por tratar, de uma maneira original, de processos como quantificação, seleção e comunicação de mensagens provenientes do espectro informacional, os estudos de Shannon tiveram grande aplicabilidade técnica e garantiram-Ihe o reconhecimento da comunidade científica. Segundo Lena Vania Pinheiro e José Mauro Loureiro (1995), os trabalhos de Shannon e Weaver, junto aos de Wiener, prenunciam o advento da ciência da informação, num contexto que a autora, em outro lugar, relaciona não apenas ao avanço científico e tecnológico impulsionado pela Segunda Guerra (que, por sua vez, resulta no que chama de "explosão bibliográfica"), mas também ao surgimento de novas tecnologias (como o computador) e à "necessidade social, histórica, 
cultural e política do registro e transmissão dos conhecimentos e informações, produto do processo de desenvolvimento da Ciência e Tecnologia" (PINHEIRO, 2002, p. 8). Conforme aponta Araújo, durante o pós guerra são criados os periódicos, eventos e associações que inauguram o projeto de construção de uma ciência da informação, que encontra na teoria de Shannon o referencial necessário para a fundamentação de uma nova disciplina "profundamente envolvida com as problemáticas da época: a necessidade militar, o clima de competição entre os países, a informação como recurso a ser usado no conflito, a necessidade de um uso instrumental e a busca por eficácia e eficiência" (ARAÚJO, 2018, p. 6).

Embora a bibliografia, a biblioteconomia e a documentação tenham desenvolvido construtos teóricos no campo dos estudos informacionais que remontam a épocas anteriores ao século $X X$, a maioria das historiografias da ciência da informação aponta a década de 1960 como o momento em que se elaboram os primeiros conceitos e se propõem as primeiras definições, despertando o debate a respeito das origens e fundamentos teóricos da nova área (PINHEIRO; LOUREIRO, 1995, p. 1). Para Pinheiro, que atribui a primeira definição formal de ciência da informação aos encontros ocorridos no Georgia Institute of Technology dos EUA em 1961 e 1962, trata-se do período de "reconhecimento do alvorecer de um novo campo científico" (PINHEIRO, 2005, p. 17), que se daria mediante a filiação majoritária dos estudos informacionais ao que Miguel Ángel Rendón Rojas (1996) chama de "teoria sintática" e Rafael Capurro (2003) de "paradigma físico" ou "epistemologia fisicista".

Entendida como fenômeno objetivo, independente dos sujeitos que com ela se relacionam e, portanto, passível de ser estudada "cientificamente", a informação assim caracterizada desprende-se dos aspectos semânticos e pragmáticos a ela relacionados, eliminando o papel ativo do sujeito cognoscente (CAPURRO, 2003, s/p). No entendimento de Araújo, ao descartar a subjetividade e a contingência como elementos componentes da informação e manter o foco na resolução de problemas técnicos, a ciência da informação opera uma redução de seu objeto de pesquisa, "considerando apenas os aspectos fisicamente observáveis e mensuráveis da informação, inserindo-se na perspectiva em voga nos contextos de pesquisa da época da Guerra Fria sintonizados com objetivos estratégicos militares" (ARAÚJO, 2018, p. 22).

A colonização da ciência pela racionalidade instrumental, fenômeno característico da era moderna que se mostra a todo vapor em meados do século XX, produz o que o filósofo frankfurtiano Herbert Marcuse (2015) chama de "pensamento unidimensional". Crítico da mesma racionalidade técnica sobre a qual a jovem ciência da informação assenta sua base teórica, Marcuse publica, em 1964, o livro O Homem Unidimensional, no 
qual lamenta a extinção da "cultura bidimensional" produzida a partir do antagonismo entre a realidade social (com seus mecanismos de alienação e conformismo) e a cultura (lugar de potencial transcendência das formas de dominação e de luta por autonomia). Para o filósofo, isso acontece pela completa incorporação da cultura à ordem estabelecida e aceitação acrítica e conformista das estruturas dominantes, fenômenos que caracterizam a ideologia da sociedade industrial avançada, alvo da análise de Marcuse.

A razão teórica, permanecendo pura e neutra, se colocou a serviço da razão prática. A aliança provou ser benéfica para ambas. Hoje, a dominação perpetua e se amplia não apenas através da tecnologia, mas como tecnologia, e a última fornece a grande legitimação do poder político em expansão, que absorve todas as esferas da cultura (MARCUSE, 2015, p. 164).

A pretensão de neutralidade axiológica alimentada por Shannon, no entanto, esbarra justamente nas dimensões semânticas e pragmáticas que sua teoria fez questão de ignorar. Conforme apontam as pesquisas de Mindell, Segal e Gerovitch (2003) sobre a recepção, em meados do século $X X$, da cibernética e da teoria da informação nos Estados Unidos, França e União Soviética, se num segundo momento as teorias de Wiener e Shannon ganham espaço na comunidade científica internacional e o trabalho dos matemáticos norte-americanos acaba sendo reconhecido e utilizado, à época da tradução alguns cientistas franceses consideraram tanto as pesquisas de Shannon quanto as de Wiener "conjecturas burguesas, cheias de mitologia e mistificação". Na União Soviética de Stalin, uma campanha anti-cibernética acusou as obras de Wiener e Shannon de serem "incorporações da idealista e reacionária pseudociência americana". Ainda segundo os autores, a tradução para o russo do artigo de Shannon, ocorrida somente em 1953, traz o texto original radicalmente modificado, sob o título de The Statistical Theory of Electrical Signal Transmission e contando com a substituição de palavras essenciais ao texto, em uma tentativa de eliminar qualquer conexão da teoria de Shannon com os campos da biologia ou das ciências sociais (pretensão jamais alimentada pelo matemático). O episódio, concluem, demonstra a "tensa relação da teoria da informação, e sua prima da Guerra Fria, a cibernética, com a ideologia e as ciências sociais nos mundos cultural e político das décadas de 1940 e 50" (MINDELL; SEGAL; GEROVITCH, 2003, s/p, tradução nossa). 
Distintas versões nacionais da cibernética e da teoria da informação não diferiram muito na gama de aplicações cibernéticas ou nos tipos de modelos matemáticos utilizados, considerando a troca ativa das mais recentes técnicas e tecnologias entre os países industrializados. A principal diferença reside nos significados políticos e culturais ligados às ideias cibernéticas (MINDELL; SEGAL; GEROVITCH, 2003, s/p, tradução nossa)

A narrativa mostra como a aparente solidez de uma ciência pura e neutra pode desmanchar-se no ar diante das formas como suas premissas serão interpretadas por diferentes culturas e em diferentes territórios, revelando a limitação hermenêutica à qual está fadada qualquer teoria que descarte as dimensões semânticas e pragmáticas de seu repertório. Não obstante, conforme já mencionado, ainda que campos como o da biblioteconomia e o da documentação já contassem com estudos dedicados aos predicados sociais da informação antes de 1945, o desenvolvimento da computação nos processos informacionais teve um impacto decisivo na predominância da "teoria sintática" e do "paradigma físico" nos anos iniciais da Guerra Fria.

Com o passar do tempo, a preocupação de cientistas e teóricos da informação com as dimensões cognitivas e sociais - ou semânticas e pragmáticas - dos estudos informacionais deu aso a uma série de perspectivas epistemológicas, que ganharam abrigo na ciência da informação especialmente a partir da década de 1970. A epistemologia social de Jesse Shera, a hermenêutica e a ética intercultural de Rafael Capurro e o neodocumentalismo de BerndFrohmann são alguns dos diversos caminhos de que cientistas da informação dispõem nos dias de hoje para trilhar suas pesquisas. No Brasil, os trabalhos de autoras como Ana Maria Pereira Cardoso (1994) - principal representante do campo de estudos denominado Informação Social, fundamentado nos princípios de historicidade dos sujeitos, totalidade dos fenômenos e tensionalidade da sociedade - e Solange Mostafa - que, em sua tese de doutorado em filosofia da educação, defende "a prática social como o centro de gravidade da prática bibliotecária" (MOSTAFA, 1985, p. 4) - revelam que, desde o século passado, "o espectro da teoria crítica ronda a ciência da informação brasileira" (BEZERRA, 2018). A teoria crítica da informação que será aqui apresentada pretende trazer mais uma contribuição para essa extensa gramática de saberes.

\section{Fundamentos teórico-metodológicos da teoria crítica}

O que é possível saber? Quais as potencialidades e limites do conhecimento humano? A busca de respostas para tais perguntas navega nos caminhos abertos pela filosofia ocidental e deságua na Europa 
moderna a partir de dois principais afluentes: o racionalismo continental de Descartes, Spinoza e Leibniz, que admite que o conhecimento pode ser atingido puramente pela razão, e o empirismo insular de Hume, Locke e Berkeley, para quem o conhecimento só pode ser alcançado a partir da experiência. Empenhado em construir uma síntese que contemplasse as virtudes e identificasse os limites de ambas as perspectivas epistemológicas, o filósofo alemão Immanuel Kant dedicou uma década inteira de sua vida a produzir uma teoria do conhecimento que desse conta de tal tarefa. O resultado de seu esforço é apresentado na obra Crítica da Razão Pura, de 1781, que se tornaria um dos trabalhos mais influentes da bibliografia filosófica iluminista, concedendo a Kant a alcunha de pai da filosofia crítica.

A teoria kantiana do conhecimento se tornaria determinante para a perspectiva crítica da geração filosófica seguinte, que tem na figura de Georg Hegel o seu principal representante em território alemão. O mesmo pode ser dito de Hegel em relação a Karl Marx e Friedrich Engels, que, antes de completarem trinta anos, já se posicionavam perante a linha de pensamento dos chamados "jovens hegelianos", em obras como $A$ Sagrada Família ou A crítica da Crítica crítica - contra Bruno Bauer e consortes (1844) e A Ideologia Alemã - crítica da mais recente filosofia alemã em seus representantes Feuerbach, B. Bauer e Stirner, e do socialismo alemão em seus diferentes profetas (1846), texto que só seria publicado integralmente em 1933. Naquele mesmo ano, a ascensão do nazismo na Alemanha levava ao exílio um grupo de intelectuais associados ao Instituto para Pesquisa Social da Universidade de Frankfurt, fundado em 1923 e conhecido na comunidade acadêmica internacional como Escola de Frankfurt. Membros do instituto, como Herbert Marcuse, Theodor Adorno e o então diretor Max Horkheimer, se encontravam engajados no estudo do pensamento de Marx, Engels e de autores marxistas como György Lukács, com vistas à construção de uma teoria crítica da sociedade - algo que desagradava o partido nazista, declaradamente antimarxista.

Em 1937, ainda à frente da direção do instituto (já então filiado à Universidade de Columbia, em Nova Iorque), Horkheimer publica o artigo Teoria tradicional e teoria crítica, que se torna uma espécie de documento inaugural da teoria crítica. Nele, estão fundamentados os princípios teóricos que irão orientar as pesquisas do instituto de Frankfurt: a historicidade dos sujeitos cognoscentes, a totalidade dos fenômenos sociais e a tensionalidade presente na sociedade. As três características, já presentes em Hegel e em Marx e Engels, podem ser encontradas nas passagens em que Horkheimer diz ser "(...) preciso passar para uma concepção que elimine a parcialidade que resulta necessariamente do fato de retirar os processos parciais da totalidade da práxis social", ou quando 
argumenta que "os homens não são apenas um resultado da história em sua indumentária e apresentação, em sua figura e seu modo de sentir, mas também a maneira como veem e ouvem é inseparável do processo de vida social tal como este se desenvolveu através dos séculos", ou, finalmente, quando afirma que "a existência da sociedade se baseou sempre na oposição direta, ou é resultado de forças contrárias; de qualquer modo não é resultado de uma espontaneidade consciente de indivíduos livres" (HORKHEIMER, 1980, p. 125).

Convidado a integrar o corpo de pesquisadores do Instituto para Pesquisa Social em 1933, Herbert Marcuse foi, ao lado de Horkheimer, um dos mais empenhados frankfurtianos a esquadrinhar os princípios teóricos e metodológicos da teoria crítica, descrita pelo autor como "uma teoria que analisa a sociedade à luz de suas capacidades - usadas e não usadas ou abusadas - de melhorar a condição humana" (MARCUSE, 2015, p. 32).

A fim de identificar e definir as possibilidades de um melhor desenvolvimento, a teoria crítica deve realizar uma abstração a partir da atual organização e utilização dos recursos da sociedade e dos resultados dessa organização e utilização. Tal abstração que se recusa a aceitar o universo dado dos fatos como o contexto final de validação, tal análise "transcendente" dos fatos à luz de suas possibilidades, impedidas e negadas, pertence à ampla estrutura da teoria social. Ela se opõe a toda metafísica em virtude do caráter rigorosamente histórico da transcendência. As "possibilidades" devem estar ao alcance da respectiva sociedade; elas devem ser metas definíveis na prática (MARCUSE, 2015, p. 33).

A perspectiva de transcendência, embora ultrapasse 0 universo material estabelecido no presente, aponta para alternativas reais de emancipação. Douglas Kellner, pesquisador e divulgador da obra de Marcuse, conta que o filósofo condenava a sociedade por seu fracasso em aplicar a tecnologia de maneiras mais emancipatórias e humanas, uma vez que defendia que "as contradições entre 'o que é' e 'o que poderia ser' fornecem um ímpeto para a mudança social" (KELLNER, 2007, p. 15). Marcuse atribui à teoria crítica a tarefa de não apenas entender por que as coisas são como são, objetivo da teoria tradicional, mas ocupar-se, também, de uma análise que transcenda a realidade a partir de suas próprias condições imanentes e descubra que as coisas poderiam ser melhores - mas não são. Isso ocorre porque há obstáculos de diversas ordens (dentre elas, e talvez principalmente, as de ordem humana, quer seja no âmbito econômico, cultural, social ou político) que impedem que 
as coisas sejam de outra forma. Identificar tais obstáculos é tarefa de ordem metodológica.

$\mathrm{Na}$ introdução de Towards a CriticalTheoryof Society, um dos seis volumes organizados por Kellner que compõem uma vasta coleção de textos de Marcuse, a metodologia da teoria crítica é sintetizada em três atos: "compreender a sociedade dada, criticar suas contradições e fracassos e construir alternativas" (KELLNER, 2007, p. 15). Para Axel Honneth, diretor do Instituto para Pesquisa Social desde 2001, são os percursos metodológicos - mais do que os princípios teóricos - que distinguem a teoria crítica de outras teorias: "epistemologicamente, os artigos de Horkheimer e Marcuse estavam voltados para uma crítica sistemática do positivismo; metodologicamente, eles visavam um conceito de pesquisa interdisciplinar" (HONNETH, 1999, p. 508).

Para lidar com as questões que coloca, a teoria crítica se propõe a realizar diagnósticos da realidade em âmbito histórico-filosófico, acrescentando a pesquisa empírica como uma segunda corrente de reflexão, em cooperação com outras disciplinas (HONNETH, 1999, p. 510). Assim é que, partindo dos fundamentos apresentados, Horkheimer se lança na aventura do que seria posteriormente chamado de "materialismo interdisciplinar", que assume como espinha dorsal a economia política (cuja crítica é feita por Marx em sua principal obra, O Capital), acrescida das contribuições da psicologia de Freud (incorporada ao pensamento de diversos frankfurtianos, como Marcuse, Walter Benjamin e Eric Fromm) e de uma teoria da cultura que permita analisar as condições culturais sob as quais ocorre a socialização dos indivíduos no sistema capitalista.

Ainda no século XIX, Marx formula um diagnóstico de grande fôlego a respeito do capitalismo, exposto em $O$ Capital. Na Dialética do Esclarecimento, publicada em 1947, Adorno e Horkheimer lançam-se no desafio de propor um diagnóstico da indústria cultural dos Estados Unidos, em efervescência na época em que os frankfurtianos chegam àquele país. Alguns anos depois, a citada obra de Marcuse se debruça sobre o fenômeno da racionalidade instrumental para propor um diagnóstico da sociedade industrial daquele momento. No mesmo diapasão, a proposta metodológica de uma teoria crítica da informação deve contemplar a realização de diagnósticos interdisciplinares que tenham como foco o ambiente informacional e as perspectivas de produção, circulação, mediação, organização, recuperação e acessibilidade da informação, identificando tanto as potencialidades quanto as contradições e os entraves à liberdade e à autonomia informacional que se colocam no cenário a ser investigado.

\section{Proposta para uma teoria crítica da informação}


Por que as coisas são como são e não de outra forma? Quais os obstáculos que impedem que as coisas sejam melhores do que são? Como agir para vencer tais obstáculos e transformar o mundo? É sobre esses três pilares que se ergue o edifício filosófico da teoria crítica.

Conforme visto, a primeira pergunta traça um horizonte fundamentalmente distinto da perspectiva positivista (ou da "teoria tradicional", nos termos de Horkheimer). Esta dedica-se a investigar e observar o mundo como ele é, para estabelecer leis e padrões que permitam a previsão de fenômenos e comportamentos - objetivos contemplados pela teoria matemática de Shannon e Weaver. A teoria crítica, por sua vez, possui um caráter transcendente: além de compreender o mundo tal como ele é, propõe um exercício de imaginação a respeito de como o mundo poderia ser. Tal exercício nada tem de utópico; antes, é construído a partir das possibilidades imanentes do mundo material. A busca por uma resposta revela que, dadas as condições reais de existência, as coisas poderiam ser melhores, mas não são. Assim, chegamos a uma nova pergunta, a respeito dos obstáculos que fazem com que as coisas sejam como são e não de outra forma. Essa pergunta, complementar à primeira, é acolhida pela teoria crítica mediante uma proposição metodológica: a realização de diagnósticos de época. Ao identificar os obstáculos que impedem que as coisas sejam melhores, o processo analítico realizado no diagnóstico pretende dar respostas a ambas as questões.

Por fim, a dúvida sobre o que deve ser feito para superar tais obstáculos exige uma solução de ordem prática, fornecida pela teoria crítica através da perspectiva da práxistransformadora, ou seja, de que a proposição de diagnósticos de época seja capaz de revelar não apenas as contradições existentes, mas também os elementos que orientam a ação com vistas à superação de tais obstáculos. Nesse sentido, o objetivo final da teoria crítica não é de ordem filosófica e intelectual, e sim ética.

A teoria crítica da informação que propomos segue os mesmos passos teóricos e metodológicos da teoria crítica, adaptando-os ao campo de investigação dos estudos informacionais por meio da absorção e integração de dois conceitos que vêm sendo discutidos na área, especialmente em congressos e publicações acadêmicas brasileiras: o conceito de regime de informação e o conceito de competência crítica em informação.

\subsection{Regime de informação}

Maria Nélida González de Gómez, filósofa e pesquisadora argentina há muito tempo radicada no Brasil, define em 1999 a chamada "sociedade da informação" como "aquela em que o regime de informação caracteriza e condiciona todos os outros regimes sociais, econômicos, culturais, das 
comunidades e do Estado" (1999, p. 2). Desde então, a autora tem se dedicado a desenvolver o conceito de regime de informação, trazendo contribuições de autores de distintos matizes de pensamento, como Sandra Braman, Mark Poster e HamidEkbia. 20 anos e muitas publicações depois, González de Gómez segue decantando suas reflexões sobre o que chama de "genealogia dos regimes de informação", destacando que a visibilidade do cenário histórico que contextualiza os usos do conceito permite observar "traços das potencialidades e fragilidades das concepções das sociedades-redes", atualizando as discussões acerca das "arquiteturas regulatórias das sociedades contemporâneas" (2019, p. 156).

O pioneirismo do uso do termo regime de informação é atribuído pela autora a Bernd Frohmann, que se vale da expressão régime of information, em uma conferência ministrada em 1995, como forma de criticar a falta de atenção de pesquisadores da ciência da informação à dimensão efetivamente política das políticas de informação. Para o filósofo,

descrever um regime de informação significa mapear os conflituosos processos que resultam em estabilizações provisórias e inquietas de conflitos entre grupos sociais, interesses, discursos e até mesmo artefatos científicos e tecnológicos" (1995, s/p.).

Atento ao caráter social da informação, Frohmann enfatiza a importância da análise das práticas que conformam desigualdades e formas de dominação em regimes específicos de informação. Com isso, o autor deseja fugir de uma visão instrumental que se limita à eficiência e eficácia de fluxos informacionais, sem considerar a mútua implicação e dependência entre ciência, tecnologia, relações sociais e discursos de poder.

Em termos gerais, tanto Frohmann quanto González de Gómez apresentam uma visão que, evitando enxergar as estruturas de um regime de informação de forma desencarnada, opere com este conceito como uma espécie de "recurso interpretativo" (nas palavras da filósofa) para investigar as relações entre política, informação e poder.

Entre as atribuições dos regimes de informação, uma das principa is seria colocar em evidência essa tensão entre as configurações socioculturais das interações em que se manifestam e constituem os diferencia is pragmáticos de informação, e as estruturações jurídico normativas, técnico-instrumentais e econômico-mercadológicas, que visam a sobre determinar essa configuração, com alguma imposição de direção ou valor" (GONZÁLEZ DE GÓMEZ, 2012, p. 56). 
As características, inquietações e tarefas que autora e autor depositam no conceito servem de inspiração para a proposta de diagnóstico daquilo que percebemos tratar-se de um novo regime de informação, tarefa a ser realizada, e de tempos em tempos atualizada, como parte de nosso programa para uma teoria crítica da informação. Em tal diagnóstico, os fenômenos de vigilância e monitoramento digital de dados pessoais de usuários da internet, filtragem algorítmica da informação, circulação de notícias falsas e demais técnicas de desinformação que grassam no regime de informação contemporâneo são considerados a partir de suas perspectivas negativas de controle, manipulação, exclusão e opressão que figuram como obstáculos à privacidade, liberdade e autonomia informacional de grupos sociais e indivíduos.

\subsection{Competência crítica em informação}

Desenvolvido na primeira década do século XXI como forma de crítica às normas e convenções institucionais associadas à competência em informação (information literacy), bem como forma de incentivo à luta de estudantes contra as estruturas de poder que sustentam a produção e a disseminação dominante da informação (TEWELL, 2015, p. 25), o conceito de competência crítica em informação complementa nossa perspectiva teórica servindo de horizonte para as perspectivas de emancipação social, a partir do desvelamento de possíveis caminhos para a práxis transformadora no cerne dos regimes de informação vigentes. A práxis, em sentido geral, representa a interação entre consciência e atividade, configurando um ciclo teórico-prático em que a teoria, posta à prova na prática, estimula a reflexão que, a partir das contradições observadas, tem o condão de alterar a teoria inicial; esta, por sua vez, é novamente posta em prática, porém sob novas circunstâncias que trazem outros desafios, e assim é submetida a uma nova reflexão, fazendo desse movimento dialético o próprio motor da história.

Com esse entendimento, Marx observa que é a partir da realidade material que os indivíduos criam suas instituições e seus deuses, e que a moral, o direito, a política e a economia são forjados a partir de circunstâncias reais e não em um plano metafísico. Em resumo, Marx compreende que é o ser social que determina a consciência, e não o contrário, como supunham os filósofos alemães perante os quais Marx estabelece um distanciamento epistemológico. Essa distância se revela de maneira explícita nas Teses sobre Feuerbach, escritas em 1845, em que Marx afirma que "toda vida social é essencialmente prática"; que "todos os mistérios que seduzem a teoria para o misticismo encontram a sua 
solução racional na práxis humana e no compreender desta práxis"; e que "a coincidência da mudança das circunstâncias e da atividade humana ou automudança só pode ser considerada e compreendida racionalmente como práxis revolucionária" (MARX, 1998, p. 99-103, grifos do autor).

$\mathrm{Na}$ conhecida tese onze, Marx escreve: "os filósofos têm apenas interpretado o mundo de maneiras diferentes; a questão, porém, é transformá-lo" (MARX, 1998, p. 103, grifos do autor). Dos pensadores que se filiaram à concepção filosófica marxista, o educador brasileiro Paulo Freire destaca-se como um dos que se mostram explicitamente engajados com a "práxis revolucionária". Sua Pedagogia do Oprimido (2016) parte da perspectiva histórica e da historicidade dos indivíduos, fornece um diagnóstico que percebe a contradição opressor-oprimido presente na realidade (e reproduzida na educação) brasileira, bem como os obstáculos que impedem tal sistema de atuar como força motriz para a emancipação popular, e propõe uma perspectiva pedagógica comprometida com a superação de tal estado de coisas. Para Freire, "se os homens são produtores desta realidade e se esta, na 'inversão da práxis', se volta sobre eles e os condiciona, transformar a realidade opressora é tarefa histórica, é tarefa dos homens" (FREIRE, 2016, p. 51).

Conforme demonstra as pesquisas de Eamon Tewell (2015) e de Arthur Bezerra e Aneli Beloni (2019), a pedagogia crítica desenvolvida por Paulo Freire é amplamente citada nas bibliografias de artigos sobre critical information literacy, seja em trabalhos estrangeiros ou em textos publicados no Brasil. Autores como Michelle Simmons (2005) e James Elmborg (2006) destacam a necessidade de desenvolver, nos estudantes, a consciência e a prática crítica para que assumam o controle de suas vidas e de seu próprio aprendizado, tornando-se agentes ativos no mundo em que vivem (ELMBORG, 2006, p. 193). Segundo Simmons, "ajudar os alunos a examinar e questionar o contexto social, econômico e político para a produção e o consumo de informações é um corolário vital para o ensino das habilidades de competência em informação" (SIMMONS, 2005, p. 299).

Podemos, nesse sentido, admitir não apenas que o caráter ativo da competência crítica em informação atende à perspectiva de prática emancipatória que integra nossa proposta de teoria crítica da informação, mas que a sua própria efetividade está condicionada ao desenvolvimento de uma consciência crítica a respeito dos regimes de informação em que os indivíduos estão inseridos, com destaque para o regime de informação dominante que vigora no ambiente digital.

\section{Considerações finais}


Para o sociólogo austríaco Christian Fuchs, uma teoria da informação que se pretenda crítica deve analisar não apenas o papel da informação e dos conceitos de informação na sociedade, na academia, na natureza, na cultura e em outras dimensões, mas também ocupar-se de identificar "como ela está relacionada aos processos de opressão, exploração e dominação, o que implica um julgamento normativo em solidariedade aos dominados e em prol da abolição da dominação" (FUCHS, 2009, p. 245). As temáticas estudadas no âmbito de tal teoria, complementa Araújo, precisam envolver questões como o "acesso à informação por parte de grupos e classes excluídos e marginalizados, a criação de formas e sistemas alternativos de informação, e mesmo estudos sobre a contrainformação, como forma de rejeição aos regimes informacionais hegemônicos" (ARAÚJO, 2009, p. 197). Queremos crer que tanto as análises sugeridas por Fuchs quanto as temáticas listadas por Araújo estão contempladas em nosso projeto.

Com a integração dos conceitos de regime de informação e competência crítica em informação, a nosso ver complementares e de certa forma interdependentes, a proposta de teoria crítica da informação que apresentamos na forma de um programa teórico-metodológico tem a pretensão de atingir a musculatura necessária para hipertrofiar, com as armas da crítica, a academia de saberes da ciência da informação, respeitando o legado das pesquisadores e pesquisadores que atuaram ou têm atuado nesse sentido. Sendo assim, concluímos o presente trabalho reformulando as problemáticas da teoria crítica, tal como foram aqui apresentadas, de modo a adaptá-las às questões que sugerimos como inspiração para futuras pesquisas e estudos críticos em informação:

1) Por que os regimes de informação são como são e não de outra forma?

2) Quais os obstáculos que impedem que os regimes de informação sejam melhores do que são?

3) Como agir para vencer tais obstáculos e transformar os regimes de informação?

\section{Referências}

ARAUJO, C. A. A. Correntes teóricas da ciência da informação. Ciência da Informação [online]. 2009, vol.38, n.3, pp.192-204.

ARAúJO, C. A. A. Manifestações (e ausências) de pensamento crítico na ciência da informação. BIBLOS - Revista do Instituto de Ciências Humanas e da Informação, v. 27, n. 2, p. 9-29, 2013.

ARAúJO, C. A. A. O que é Ciência da Informação. Belo Horizonte: KMS, 2018. 
BEZERRA, A. C. Contribuição da Teoria Crítica aos estudos sobre regime de informação e competência crítica em informação. Anais do XIX ENANCIB - Encontro Nacional de Pesquisa em Ciência da Informação, Londrina, 2018.

BEZERRA, A. C.; BELONI, A. Os sentidos da "crítica" nos estudos de competência em informação. Em Questão, Porto Alegre, v. 25, n. 2, p. 208-228, maio/ago. 2019

CARDoso, A. M. P.Retomando possibilidades conceituais: uma contribuição à sistematização do campo da informação social. Revista da Escola de Biblioteconomia da UFMG, v. 23, n. 2, p. 107-114, 1994.

CAPURRO, R. Epistemologia e Ciência da Informação. In: ENANCIB Encontro Nacional de Pesquisa em Ciência da Informação, 5, 2003. Anais... Belo Horizonte, 2003.

ELMBORG, J. Critical information literacy: implications for instructional practice. The journal of academic librarianship, v. 32, n. 2, p. 192-199, 2006.

FREIRE, P. Pedagogia do Oprimido. São Paulo: Paz e Terra, 2016.

FROHMANN, B. Taking information policy beyond information science: applying the actor network theory. ANNUAL CONFERENCE OF THE CANADIAN ASSOCIATION FOR INFORMATION SCIENCE, 23,1005; Proceedings...Edmonton, Alberta, 7-10 de Junho, 1995.

FUCHS, C. Towards a Critical Theory of Information. TripleC, 7(2): 2009, pp.243-292.

GONZÁLEZ DE GÓMEZ, M. N. O caráter seletivo das ações de informação. Informare, Rio de Janeiro, v. 5, n. 2, p. 7-31, 1999.

GONZÁLEZ DE GÓMEZ, M. N. Regime de informação: construção de um conceito. Informação \& sociedade: estudos, João Pessoa, v. 22, n. 3, p. 43-60, 2012.

GONZÁLEZ DE GÓMEZ, M. N. Reflexões sobre a genealogia dos regimes de informação. Informação \& sociedade: estudos, João Pessoa, v.29, n.1, p. 137-158, jan./mar. 2019.

HOBSBAWM, E. A era dos extremos:o breve século XX (1914-1991). São Paulo: Companhia das Letras, 1995. 
HONNET, A. Teoria crítica. In: GIDDENS, A.; TURNER, J. Teoria social hoje. São Paulo: UNESP, 1999.

HORKHEIMER, M. Teoria Tradicional e Teoria Crítica. In: BENJAMIN, W., HORKHEIMER, M., ADORNO, T. W., HABERMAS, J. Textos escolhidos. (Coleção Os Pensadores). São Paulo: Abril Cultural, 1980.

KELLNER, D. Introduction. In: KELLNER (org.). Towards a Critical Theory of Society. London and New York: Routledge Press, 2007.

MARCUSE, H. O homem unidimensional: estudos da ideologia da sociedade industrial avançada. São Paulo: EDIPRO, 2015.

MARX, K. Teses sobre Feuerbach. In: MARX, K.; ENGELS, F. A ideologia alemã.São Paulo: Martins Fontes, 1998.

MINDELL, D.; SEGAL, J.; GEROVITCH, S. Cybernetics and Information Theory in the United States, France and the Soviet Union. In: WALKER, Mark. Science and Ideology: A Comparative History. London: Routledge, 2003, p. 66-95.

MOSTAFA, S. P. Epistemologia da Biblioteconomia. 1985. Tese (Doutorado em Educação) - Pontifícia Universidade Católica de São Paulo, São Paulo, 1985.

PINHEIRO, L. V. R. A ciência da informação entre luz e sombra: domínio epistemológico e campo interdisciplinar. Rio de Janeiro. Tese (Doutorado em Comunicação) - Universidade Federal do Rio de Janeiro, Rio de Janeiro, 1997.

PINHEIRO, L. V. R. Gênese da Ciência da Informação ou sinais anunciadores da nova área. In: AQUINO, M.A. O campo da Ciência da Informação: gênese, conexões e especificidades. João Pessoa, UFPB, 2002. P.61-86

PINHEIRO, L. V. R. Processo evolutivo e tendências contemporâneas da ciência da informação. Inf. \& Soc., Est., João Pessoa, v. 15, n. 1, p. 1348, jan./jun. 2005.

PINHEIRO, L. V. R. LOUREIRO, J. M. M. Traçados e limites da Ciência da Informação. Ciência da Informação, Brasília: v. 24, n. 1, p. 42-53, jan./jul.1995.

SEALE, M. The Neoliberal Library. In: GREGORY, L.; HIGGINS, S. Information Literacy and Social Justice: Radical Professional Praxis. Library Juice Press, 2013, pp. 39-61. 
SHANNON, C.; WEAVER, W. The Mathematical Theory of Communication. Illinois: University of Illinois Press, 1964.

SIMMONS, M. H. Librarians as disciplinary discourse mediators: using genre theory to move toward critical information literacy. Libraries and the Academy, Baltimore, v. 5, n. 3, p. 297-311, 2005. 